\section{International Journal of Medical Research and Review}

\title{
Prevalence and clinical profile of patients with resistant hypertension
}

\author{
Umamaheswari B. ${ }^{1}$, Suganya P. ${ }^{2 *}$, Revathi A. ${ }^{3}$ \\ DOI: https://doi.org/10.17511/ijmrr.2019.i06.04 \\ 1 Umamaheswari B., Assistant Professor, Department of General Medicine, Institute of Social Obstetrics, Government Kasturba Gandhi \\ General Hospital, Madras Medical College, Chennai, Tamil Nadu, India. \\ 2* P. Suganya, Assistant Professor, Department of General Medicine, Government Medical College, Omandurar Government Estate, Chennai, \\ Tamil Nadu, India. \\ 3 A Revathi, Assistant Professor, Department of General Medicine, Institute of Social Obstetrics, Government Kasturba Gandhi General \\ Hospital, Madras Medical College, Chennai, Tamil Nadu, India.
}

Objective: To find prevalence and clinical profile of patients with resistant hypertension. Methods: In a Prospective Observational Study, 100 Hypertensive patients were evaluated in Hypertension OPD, Medical OPD, and Medical Wards. Hypertensive Patient on more than 3 drugs with uncontrolled BP were included for this study. Patients were subjected to Clinical examination, Laboratory investigations and Ultrasound. BP is recorded in all 4 limbs with appropriate cuff size, Patients drug history (Both antihypertensive and other medications for concomitant illness will be enquired), Physical activity and Drug compliance were enquired. Result: Among the 100 patients studied, 18\% patients were found to have Resistant hypertension. Of this, 5 patients were in incorrect drug combination, 7 patients were not drug compliant, 12 patients had Uncontrolled Diabetes, 15 patients had Dyslipidemia, 6 patients had Medical Renal disease, 2 patients had Fatty Liver, 1 patient had Contracted Kidney and 1 patient had Aortailiac Thrombosis. Conclusion: Incorrect Drug prescription, non-adherence to drugs and metabolic factors played a major role in resistant hypertension in the present study group.

Keywords: Diabetes, Dyslipidemia, Resistant Hypertension

Corresponding Author

P. Suganya, Assistant Professor, Department of General Medicine, Government Medical College, Omandurar Government Estate, Chennai, Tamil Nadu, India.

Email: drsuganyamani@gmail.com

\section{How to Cite this Article}

Umamaheswari B, Suganya P, Revathi A. Prevalence and clinical profile of patients with resistant hypertension. Int J Med Res Rev. 2019;7(6):461467.

Available From

https://ijmrr.medresearch.in/index.php/ijmrr/article/ view/1095

\section{To Browse}

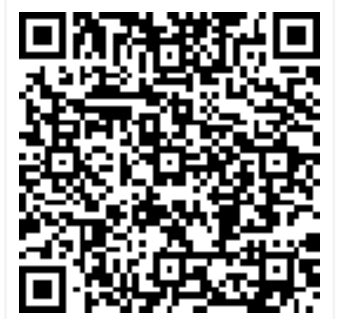

Manuscript Received 2019-10-10

Conflict of Interest No

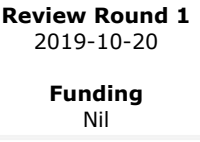

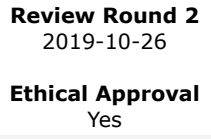

Review Round 3

Plagiarism X-checker $8 \%$
Accepted 2019-10-30

Note

(c) 2019 by Umamaheswari B., P. Suganya, A Revathi and Published by Siddharth Health Research and Social Welfare Society This is an Open Access article licensed under a Creative Commons Attribution 4.0 International License https://creativecommons.org/licenses/by/4.0/ unported [CC BY 4.0]. 


\section{Introduction}

Hypertension is a non-communicable disease associated with long term morbidity and higher mortality. It causes a major global burden of disease. The incidence of hypertension is on increasing trend because of changing lifestyle, food pattern and increasing urbanization.

The prevalence of resistant hypertension as defined by criteria, when blood pressure is more than $140 / 90$ despite of adequate full doses of 3 different drug classes of drugs, one of them should be a diuretic, is on increasing trend among the hypertensive individual [1]. The risk of cardiovascular morbidity and mortality is higher among patients with resistant hypertension than among those whose hypertension is well controlled $[1,2]$.

Hence, all the effort has to be made to identify causes for secondary hypertension, which may be contributing, or any correctable cause has to be identified. This may be due to pseudo resistant hypertension such as white coat hypertension or due to thickening of vessels as seen in elderly individual or due to true hypertension. Resistant hypertension prevalence estimated to be $12.8 \%$ in a large cohort study with higher rates in black race and obesity and little higher rate found in males and older age $[3,4,5]$.

\section{Materials and Methods}

Place of study: Department of General Medicine, Hypertension OPD, Medical OPD, Medical Wards Govt. Kasturibai Gandhi Memorial Hospital, Chennai - 600005.

Sample size: 100

Duration: July 2018 To January 2019

Study design: Prospective Observational Study

Inclusion criteria: Hypertensive patients with Age group of 40 to 70 years

\section{Exclusion criteria}

01 . Age $<40$ years and $>70$ years

02. Patient with known secondary causes of hypertension

\section{Methodology}

01. Patient who are known case of hypertensive on more than 3 drugs with uncontrolled BP are included for this study.
Patients will be subjected to Clinical examination, Laboratory investigations and Ultrasound. The final analysis will be made at the end of the study to achieve the aforementioned goals.

02. BP is recorded in all 4 limbs with appropriate cuff size.

03. Patients drug history (Both antihypertensive and other medications like usage of NSAIDS, Aspirin, and Acetaminophen for concomitant illness were enquired).

04. Patients physical activity was enquired.

05. Patients drug compliance was enquired. Morisky questionnaire was utilized to assess adherence to antihypertensive medications, following which all cases of $\mathrm{RH}$ were further classified into those with pseudo-resistance and those with true resistant hypertension.

06. Patients will be subjected to basic investigation.

07. ECG, Echo and USG abdomen (To assess renal size) were done.

08. Depending upon patient's profile, Patient were subjected to optional investigations like Thyroid profile test, Serum Cortisol, Urine metanephrine, Renal Doppler/ARR (Angiotensin Renin ratio)

- Classification of blood pressure (JNC SEVEN)

01. Normal: sys $<120 \mathrm{mmHg}$ and dias $<80 \mathrm{mmHg}$

02. Pre-hypertension: sys $-120-139 \mathrm{mmHg}$ and dias$80-89 \mathrm{mmHg}$

03. Stage 1 hypertension: sys $-140-159 \mathrm{mmHg}$ and dias-90-99mmHg

01 . Stage 2 hypertension: sys $>160 \mathrm{mmHg}$ and dias $>100 \mathrm{mmHg}$

02. Isolated systolic hypertension: sys $>140 \mathrm{mmHg}$ and dias $<90 \mathrm{mmHg}$

\section{Results}

Among the 100 patients studied, 39 patients were found to be in the age group of 40-50. This constitutes $39 \%$ of the study group. 40 patients were found to be in the age group of 51-60.

This constitutes $40 \%$ of the study group. 21 patients were found to be in the age group of 61 70. This constitutes $21 \%$ of the study group. There were no patients above age group of 70 in this study (Table 1 ). 
Table-1: Age distribution.

\begin{tabular}{|l|l|l|}
\hline \multicolumn{1}{|c|}{ Age (years) } & Number of patients & Percentage (\%) \\
\hline $40-50$ & 39 & 39 \\
\hline $51-60$ & 40 & 40 \\
\hline $61-70$ & 21 & 21 \\
\hline Total & 100 & 100 \\
\hline
\end{tabular}

Among the 100 patients studied, 52 patients were females. This constitutes $52 \%$ of the study group. 48 patients were males. This constitutes $48 \%$ of the study group (Table 2).

\section{Table-2: Gender distribution.}

\begin{tabular}{|l|l|l|l|l|}
\hline Gender & Frequency & Percent & Valid Percent & Cumulative Percent \\
\hline Female & 52 & 52.0 & 52.0 & 52.0 \\
\hline Male & 48 & 48.0 & 48.0 & 100.0 \\
\hline Total & 100 & 100.0 & 100.0 & \\
\hline
\end{tabular}

Among the 100 patients studied, 15 patients were found to be in Stage I hypertension. 67 patients were found to be in Stage 2 hypertension. 18 patients were found to have resistant hypertension (Table 3).

Table-3: Patient distribution by stages of hypertension.

\begin{tabular}{|l|l|l|l|l|l|}
\hline $\begin{array}{c}\text { Stages of } \\
\text { hypertension }\end{array}$ & \multicolumn{2}{|l|}{ Frequency } & $(\%)$ & \multicolumn{1}{|c|}{$\begin{array}{c}\text { Valid } \\
\text { Percent }\end{array}$} & \multicolumn{1}{c|}{$\begin{array}{c}\text { Cumulative } \\
\text { Percent }\end{array}$} \\
\hline \multirow{2}{*}{ Stage 1} & No & 85.0 & 85.0 & 85.0 & 85.0 \\
\cline { 2 - 7 } & Yes & 15.0 & 15.0 & 15.0 & 100.0 \\
\hline \multirow{2}{*}{ Stage 2 } & No & 33.0 & 33.0 & 33.0 & 33.0 \\
\cline { 2 - 7 } & Yes & 67.0 & 67.0 & 67.0 & 100.0 \\
\hline \multirow{2}{*}{$\begin{array}{l}\text { Resistant } \\
\text { Hypertension }\end{array}$} & No & 82.0 & 82.0 & 82.0 & 82.0 \\
\cline { 2 - 7 } & Yes & 18.0 & 18.0 & 18.0 & 100.0 \\
\hline
\end{tabular}

Among the 100 patients studied, 18 patients were found to have Resistant Hypertension. In this, 13 patients were found have correct drug combination. This constitutes $72.22 \%$ of the Resistant Hypertensive patients. 5 patients were found not to be in correct drug combination. This constitutes $27.78 \%$ of Resistant Hypertensive patients (Table4).

Table-4: Drug prescription in resistant hypertension.

\begin{tabular}{|l|l|}
\hline \multicolumn{1}{|c|}{ Number of patients } & \multicolumn{1}{c|}{$\%$ of Patients } \\
\hline Correct & 13 \\
\hline Incorrect & 5 \\
\hline Total & 18 \\
\hline
\end{tabular}

Among the 100 patients studied, 18 patients were found to have Resistant Hypertension. In this 11 patients were found be drug compliant. This constitutes $61.10 \%$ of the Resistant Hypertensive patients.
7 patients were not found to be drug compliant. This constitutes $38.90 \%$ of the Resistant Hypertensive patients (Table 5).

Table-5: Drug compliance in resistant hypertension.

\begin{tabular}{|l|l|l|}
\hline & \multicolumn{1}{|c|}{ Number of patients } & \multicolumn{1}{c|}{$\%$ of patients } \\
\hline Compliant & 11 & 61.10 \\
\hline Non-compliant & 7 & 38.90 \\
\hline Total & 18 & 100.00 \\
\hline
\end{tabular}

Among the 100 patients studied, 18 patients were found to have resistant hypertension. In these 6 patients were found to have resistant hypertension due to other drugs. This constitutes $33.3 \%$ of the resistant hypertensive patients. 11 patients were found to be not on any other drugs. This constitutes $66.7 \%$ of resistant hypertensive patients (Table 6 ).

Table-6: Other drugs contributing to resistant hypertension.

\begin{tabular}{|l|l|l|}
\hline & \multicolumn{1}{|c|}{ Number of patients } & $\%$ of patients \\
\hline Not Contributing & 12 & 66.7 \\
\hline Contributing & 6 & 33.3 \\
\hline Total & 18 & 100.0 \\
\hline
\end{tabular}

Among the 100 patients studied, 18 patients were found to have resistant hypertension. In these 12 patients were found to have resistant hypertension due to diabetes. This constitutes $66.7 \%$ of the resistant hypertensive patients. 15 patients were found to have dyslipidemia. This constitutes $83.33 \%$ of resistant hypertensive patients (Table 7 ).

Table-7: Prevalence of modifiable risk factors in resistant hypertension.

\begin{tabular}{|l|l|l|}
\hline & Number of patients & $\%$ of total hypertensive patients \\
\hline Diabetes & 12 & 66.7 \\
\hline Dyslipidemia & 15 & 83.33 \\
\hline
\end{tabular}

Among the 100 patients studied, 18 patients were found to have resistant hypertension. In these 6 patients were found to have elevated renal parameters. This constitutes $33.33 \%$ of the resistant hypertensive patients. 12 patients were found to have normal renal parameters. This constitutes $66.67 \%$ of resistant hypertensive patients (Table 8 ).

Table-8: Renal parameters in resistant hypertension.

\begin{tabular}{|l|l|l|}
\hline & Number of patients & $\%$ of total hypertensive patients \\
\hline Elevated & 6 & 33.33 \\
\hline Normal & 12 & 66.67 \\
\hline
\end{tabular}


Among the 100 patients studied, 18 patients were found to have resistant hypertension. In these 6 patients were found to have Medical Renal disease. This constitutes $33 \%$ of the resistant hypertensive patients. 2 patients were found to have Fatty Liver. This constitutes $11 \%$ of resistant hypertensive patients. 1 patient was found to have Contracted Kidney. This constitutes $6 \%$ of resistant hypertensive patients. 1 patient is found to have Aortailiac Thrombosis. This constitutes $6 \%$ of resistant hypertension patients. 8 patients were found to be normal. This constitutes $44 \%$ of resistant hypertension patients (Table 9).

Table-9: Ultrasound in resistant hypertension.

\begin{tabular}{|l|l|l|l|l|l|}
\hline & Normal & MRD & $\begin{array}{c}\text { Fatty } \\
\text { Liver }\end{array}$ & $\begin{array}{c}\text { Contracted } \\
\text { Kidney }\end{array}$ & $\begin{array}{c}\text { Aortailiac } \\
\text { Thrombosis }\end{array}$ \\
\hline Ultrasound & 8 & 6 & 2 & 1 & 1 \\
\hline
\end{tabular}

\section{Discussion}

This was a prospective observational study among 100 hypertensive individuals. They were catagorised according to the age, gender, stages of hypertension. Their clinical profile, drug prescription, compliance and other drugs contributing to hypertension were evaluated.

The prevalence of $\mathrm{RH}$ among the present study population was $18 \%$ [6]. This finding is consistent with other observational studies conducted in Europe and North America. In the Controlled Onset Verapamil Investigation of Cardiovascular Endpoints trial, the prevalence of $\mathrm{RH}$ was $18 \%$. Prior studies have often over-estimated tRH without ruling out pseudo-resistance.

Pseudo resistance can be caused by various factors, including inaccurate measurement of $\mathrm{BP}$, poor adherence $(61.1 \%$ in the present study) or suboptimal treatment regimens (27.78\%), physician's inertia or white-coat effect, produces a false impression of tRH if not taken into account [8]. The incapacity of ruling out pseudo-resistance is very important in order to avoid over treatment and avoid complications.

The limited data gathered from the studies conducted in the neighboring Southeast Asian countries show that the prevalence of Resistant Hypertension is on the rise $[9,10,11]$. According to Daugherty et al., approximately 1 in 6 patients on 3 or more antihypertensive drugs will continue to meet the criteria for RH after 1 year [12].
Physicians can expect to encounter RH one in every ten hypertensive patients on treatment. This situation isworrisome and highlights that treatment resistant BP will continue to be a clinically important hypertension phenotype. A study carried on hypertensive patients reported that prevalence of $\mathrm{RH}$ increased with age, particularly in females as compared to males; implying that gender and age may be used to predict development of RH [13].

Moreover, it was also observed that a significant association with the female gender. Several studies have reported sexual dimorphism in BP such that incidence of hypertension is much higher in males during early adulthood, but this level alters after the sixth decade of life.

The rise in the BP after the age of 55 is steeper in females as compared to males, which also shows features of treatment resistance [1]. Women are more likely to have difficulty adhering to optimum $\mathrm{BP}$, have a higher prevalence of co-morbidities and obesity influenced by estrogen withdrawal and, therefore, are more likely to develop RH.

It was observed that an increased use of painkillers contributes to the poor control found in $\mathrm{RH}$. Increased use of non-narcotic analgesics including the NSAIDs, aspirin and acetaminophen are contributing agents concerning BP control $[14,15]$. This is established in the literature $[16,17]$. The number of people consuming excessive painkillers were not aware of the side effects of these drugs and their role in reducing the efficacy of the BP control by antihypertensive drugs.

In addition, painkillers like acetaminophen, have been found to develop hypertension [15] but in comparison to NSAIDS (particularly ibuprofen), acetaminophen are less likely to worsen BP control in already treated patients [16] hence these medications should be avoided or withdrawn in resistant hypertensive patients. Since it is clinically very difficult, the lowest effective dose should be administered as and when needed.

In the present study, it was observed that a strong association between diabetes mellitus and resistant hypertension. This observation is concordant with other previous studies which have shown a positive relation $[3,13,18]$. "Blood pressure control in diabetes is extremely important," says Dr. Fonseca. "It has a huge impact on complications, particularly nephropathy, and cardiovascular events." 
It has been shown that chronic kidney disease and advanced retinopathy are significantly higher in individuals with resistant hypertension than in those with nonresistant hypertension or uncontrolled hypertension. Patients with resistant hypertension were older, more frequently women, and had significantly higher waist circumference, albuminuria and serum creatinine, and lower glomerular filtration rate [19].

In the present study, dyslipidemia was seen in 15 patients that contributes to $83.33 \%$ of the study population. This corresponds to the Framingham Heart Study data on the hypertensive population reported that more than $80 \%$ had at least one additional cardiovascular disease risk factor and predominantly these risk factors were atherogenic in nature. Studies have consistently indicated that hypertension and hypercholesterolemia frequently coexist, causing what is known as dyslipidemic hypertension $(\mathrm{DH})[20,21]$.

The risk of CVD associated with concomitant hypertension and dyslipidemia is more multiplicative than the sum of the individual risk factors $[22,23]$ the coexistence of dyslipidemic hypertension has been termed as 'LIPITENSION'. There is some evidence to suggest that treating dyslipidemia has beneficial effects on blood pressure (BP).

Studies by Borghi et al.,[24,25] have found that patients receiving concomitant antihypertensive and statin therapy experienced a reduction in BP that could not be explained solely by the lipid-lowering effect of the statin or the effect of the antihypertensive medication. These results suggest that the use of statins in combination with antihypertensive drugs may improve BP control in patients, with uncontrolled hypertension and high serum cholesterol levels.

This study has few limitations. First, the sampling data was collected from a single tertiary care hospital. Secondly, when compared to the prevalence of Hypertension in general population the sample size used in this study is small.

Thirdly, the data like adherence to the drug and other contributing drugs like painkillers were collected orally from the patients. However, the data correlates with the findings of previous studies discussed here. These points, which are important, can help better understand the key role players in the development, progression and prognosis of $\mathrm{RH}$.

\section{Conclusion}

Hypertension is a non-communicable disease with increasing trend having both modifiable and nonmodifiable factors. The stage of hypertension increases with increase in age. In the present study $15 \%$ were in stage 1 hypertension, $67 \%$ were in stage 2 hypertension and $18 \%$ were in resistant hypertension. The major factors contributing to resistant hypertension in the present study were

- Incorrect / Suboptimal drug prescription, which contributes to about $27.78 \%$

- Non-Compliance of drug, which contributes to about $61.10 \%$

- Consumption of other drugs for co-existing illness, which contributes to about 33.3\%

- The other metabolic factors such as

- Uncontrolled diabetes which contributes to about $66.7 \%$

- Dyslipidemia which contributes to about $83.3 \%$ Should be addressed

01. Adequate knowledge of pharmacology is essential for dosing and in choosing a right combination of antihypertensive drugs in order to overcome the problem of resistant hypertension.

02. In patients with resistant hypertension, the patient should be personally interviewed to check whether he is consuming other commonly used over the counter drugs that could hamper adequate control of blood pressure.

\section{What the study adds to the existing knowledge?}

As in other similar studies done in various places, the present study also supports the fact that pseudo resistant hypertension is more common than true resistant hypertension. In patients with resistant hypertension it is mandatory for the physician to personally verify whether right drug has been delivered to him and whether he is taking as prescribed.

\section{Author's contributions}

Dr. Umamaheswari B: Concept, study design.

Dr. P. Suganya: Manuscript preparation, data analysis. 
Dr. A Revathi: Data analysis

\section{Reference}

01. Calhoun DA, Jones D, Textor S, Goff DC, Murphy $T P$, Toto RD, et al. Resistant hypertension: diagnosis, evaluation, and treatment- A scientific statement from the American Heart Association Professional Education Committee of the Council for High Blood Pressure Research. Hypertension. 2008;51(6)1403-1419. doi: 10.1161/hypertensionaha.108.189141 [Crossref]

02. Pierdomenico SD, Lapenna D, Bucci A, Di Tommaso R, Di Mascio R, Manente BM, et al. Cardiovascular outcome in treated hypertensive patients with responder, masked, false resistant, and true resistant hypertension. Am J Hypertens. 2005;18(11)1422-1428.

doi: 10.1016/j.amjhyper.2005.05.014 [Crossref]

03. Persell SD. Prevalence of resistant hypertension in the United States, 2003-2008. Hypertension. 2011;57(6)1076-1080.

doi: 10.1161/hypertensionaha.111.170308 [Crossref]

04. Egan BM, Zhao Y, Axon RN, Brzezinski WA, Ferdinand KC. Uncontrolled and apparent treatment resistant hypertension in the United States, 1988 to 2008. Circulation. 2011;124(9)1046-1058.

doi: 10.1161/circulationaha.111.030189 [Crossref]

05. Lotufo PA1, Pereira AC, Vasconcellos PS, Santos IS, Mill JG, Bensenor IM. Resistant hypertension- risk factors, subclinical atherosclerosis, and comorbidities among adults-the Brazilian Longitudinal Study of Adult Health (ELSA-Brasil). J Clin Hypertens (Greenwich). 2015;17(1)74-80.

doi: $10.1111 /$ jch.12433 [Crossref]

06. Black HR, Elliott WJ, Grandits G, Grambsch P, Lucente $T$, White WB, et al. Principal results of the Controlled Onset Verapamil Investigation of Cardiovascular End Points (CONVINCE) trial. JAMA. 2003;289(16)2073-2082.

doi: $10.1001 /$ jama.289.16.2073 [Crossref]
07. Calhoun DA, Jones D, Textor S, Goff DC, Murphy TP, Toto RD, et al. Resistant hypertension: diagnosis, evaluation, and treatment- a scientific statement from the American Heart Association Professional Education Committee of the Council for High Blood Pressure Research. Circulation. 2008;117(25)e510-e526.

doi: 10.1161/circulationaha.108.189141 [Crossref]

08. Barochiner J, Alfie J, Aparicio LS, Cuffaro PE, Rada MA, Morales MS, et al. Prevalence and clinical profile of resistant hypertension among treated hypertensive subjects. Clin Exp Hypertens. 2013;35(6)412-417.

doi: $\quad 10.3109 / 10641963.2012 .739236 \quad$ [Crossref]

09. Saleem F, Hassali AA, Shafie AA. Hypertension in Pakistan- time to take some serious action. $\mathrm{Br}$ J Gen Pract. 2010;60(575)449-450. doi: 10.3399/bjgp10X502182 [Crossref]

10. Leenen $\mathrm{FH}$, Dumais J, McInnis $\mathrm{NH}$, Turton $\mathrm{P}$, Stratychuk L, Nemeth $\mathrm{K}$, et al. Results of the Ontario survey on the prevalence and control of hypertension. CMAJ. 2008;178(11)1441-1449. doi: $10.1503 / \mathrm{cmaj} .071340$ [Crossref]

11. Kumara WA, Perera T, Dissanayake $M$, Ranasinghe $\mathrm{P}$, Constantine GR. Prevalence and risk factors for resistant hypertension among hypertensive patients from a developing country. BMC Res Notes. 2013;6;373. doi: 10.1186/1756-0500-6-373 [Crossref]

12. Daugherty SL, Powers JD, Magid DJ, Tavel HM, Masoudi FA, Margolis $\mathrm{KL}$, et al. Incidence and prognosis of resistant hypertension in hypertensive patients. Circulation. 2012;125(13)1635-1642.

doi: 10.1161/circulationaha.111.068064 [Crossref]

13. Sim JJ, Bhandari SK, Shi J, et al. Characteristics of resistant hypertension in a large ethnically diverse hypertension population of an integrated health system. Mayo Clin Proc. 2013;88(10)1099-1107.

doi: $\quad 10.1016 /$ j.mayocp.2013.06.017 [Crossref] 
14. Dedier J, Stampfer MJ, Hankinson SE, Willett WC, Speizer FE, Curhan GC. Nonnarcotic analgesic use and the risk of hypertension in US women. Hypertens. 2002;40(5)604-608; discussion 601-3.

doi: 10.1161/01.hyp. 0000035856.77718.da [Crossref]

15. Forman JP, Stampfer MJ, Curhan GC. Nonnarcotic analgesic dose and risk of incident hypertension in US women. Hypertens. 2005;46(3)500-507.

doi: $\quad 10.1161 / 01$. HYP.0000177437.07240.70 [Crossref]

16. Radack KL, Deck CC, Bloomfield SS. Ibuprofen interferes with the efficacy of antihypertensive drugs- A randomized, double-blind, placebocontrolled trial of ibuprofen compared with acetaminophen. Ann Intern Med. $1987 ; 107(5) 628-635$.

doi: $10.7326 / 0003-4819-107-5-628$ [Crossref]

17. Conlin PR, Moore TJ, Swartz SL, Barr E, Gazdick $L$, Fletcher $C$, et al. Effect of indomethacin on blood pressure lowering by captopril and losartan in hypertensive patients. Hypertens. $2000 ; 36(3) 461-465$.

doi: 10.1161/01.hyp.36.3.461 [Crossref]

18. Solini A, Zoppini G, Orsi E, Fondelli C, Trevisan $R$, Vedovato $M$, et al. Resistant hypertension in patients with type 2 diabetes- clinical correlates and association with complications. J Hypertens. 2014; 32(12)2401-2410; discussion 2410.

doi: $10.1097 / \mathrm{HJH} .0000000000000350$ [Crossref]

19. V Fonseca. Management of Patients with Diabetes and Resistant Hypertension. 2016. [Crossref]

20. Williams RR, Hunt SC, Hopkins PN, Stults BM, Wu LL, Hasstedt SJ, et al. Familial dyslipidemic hypertension- Evidence from 58 Utah families for a syndrome present in approximately $12 \%$ of patients with essential hypertension. JAMA. $1988 ; 259(24) 3579-3586$.

doi: $10.1001 /$ jama.259.24.3579 [Crossref]
21. Haffner SM, Miettinen $H$, Gaskill SP, Stern MP. Metabolic precursors of hypertension- The San Antonio Heart Study. Arch Intern Med. 1996;156(17)1994-2001.

doi: $\quad 10.1001 /$ archinte.1996.00440160106013 [Crossref]

22. Stamler J, Wentworth D, Neaton JD. Prevalence and prognostic significance of hypercholesterolemia in men with hypertensionProspective data on the primary screenees of the Multiple Risk Factor Intervention Trial. Am J Med. $1986 ; 80(2 A) 33-39$.

doi: $10.1016 / 0002-9343(86) 90158-0$ [Crossref]

23. Castelli WP, Anderson K. A population at riskPrevalence of high cholesterol levels in hypertensive patients in the Framingham Study. Am J Med. 1986;80(2A)23-32.

doi: 10.1016/0002-9343(86)90157-9 [Crossref]

24. Borghi C, Prandin MG, Costa FV, Bacchelli S, Degli Esposti D, Ambrosioni E. Use of statins and blood pressure control in treated hypertensive patients with hypercholesterolemia. ] Cardiovasc Pharmacol. 2000;35(4)549-555.

doi: 10.1097/00005344-200004000-00006 [Crossref]

25. Borghi C, Dormi A, Veronesi M, Sangiorgi Z, Gaddi A, Party BH. Association between different lipid-lowering treatment strategies and blood pressure control in the Brisighella Heart Study. American Heart J. 2004;148(2)285-292. doi: 10.1016/j.ahj.2004.02.003 [Crossref] 